\title{
Violent Children: Bridging Development, Intervention, and Public Policy
}

\author{
Gregory S. Pettit \\ Auburn University
}

\author{
Kenneth A. Dodge \\ Duke University
}

\begin{abstract}
Childhood violence is a major public health and social policy concern in the United States. Scientists and policymakers alike have increasingly turned their attention to the causes of childhood violence and the extent to which its course can be modified through well-planned preventive interventions. However, it is not apparent that policymakers draw upon basic research findings in formulating their priorities and policies, nor is it apparent that developmental scientists incorporate policy considerations and prevention findings into their research frameworks and designs. The goal of this special issue on violent children is to begin to bridge the gaps among basic developmental science, prevention science, and public policy.
\end{abstract}

Contained in this issue are the products of a call for papers for a special issue of Developmental Psychology focused on violent children. Childhood violence, broadly construed, continues to be a major health concern and social policy focal point in the United States. The national spotlight shines more brightly on violent children and the circumstances of their lives when tragic events, extensively covered by the media, occupy public and policymaker attention (e.g., Bipartisan Working Group on Youth Violence, 1999; Moore, Petrie, Braga, \& McLaughlin, 2002). In spite of enormous attention to the issue, clinical practice and public policy have not had a significant impact on reducing the childhood violence rate (short-term vacillations in crime and delinquency rates notwithstanding). There is a need for sustained momentum and creativity in our efforts to understand better the developmental course of childhood violence and the factors associated with its growth and its decline. Furthermore, a need exists for developmental psychology to have an impact on the formulation, implementation, and evaluation of science-based prevention and intervention programs and public policies. Moreover, there is a need to bring together these often disparate efforts to ensure that developmental science, prevention, and public policy work in tandem and inform one another.

Our reading of the childhood antisocial behavior and violence literatures suggests the need for greater synthesis and integration. Although there have been some noteworthy recent attempts to assemble collections of articles devoted to youth violence involvement (Weist \& Cooley-Quille, 2001), aggression and antisocial behavior in school settings (Smith \& Furlong, 1998), and socialpolicy implications of research on childhood psychopathology (Cicchetti \& Toth, 2000), such collections are unlikely to reach the audience that is served by Developmental Psychology. The ab-

Gregory S. Pettit, Department of Human Development and Family Studies, College of Human Sciences, Auburn University; Kenneth A. Dodge, Center for Child and Family Policy, Duke University.

Correspondence concerning this article should be addressed to Gregory S. Pettit, Department of Human Development and Family Studies, College of Human Sciences, Auburn University, Auburn, Alabama 36849. E-mail: gpettit@auburn.edu sence of any compilation of scientific research on childhood violence in a major developmental journal may have contributed to (as well as reflect) the existing fragmentation in the literature, the erratic media attention given to important findings emerging from developmental research, and, perhaps concomitantly, a lessened role of developmental science in informing public-policy decision making. Thus, the rationale can be discerned for this special issue: We sought to assemble a collection of articles that is more explicitly concerned with bridging the gaps among basic developmental inquiry, implementation and evaluation of violence prevention programs, and the testing of social policies that might be expected to be directly implicated in childhood violence. Authors were asked to be as clear and concise as possible as to the implications of their discoveries for practice and policy. We hoped, in pursuing these goals, that basic scientific contributions to the study of childhood violence might achieve greater visibility than has been the case in the past.

We believe that the resulting set of articles, submitted through an open call for papers and evaluated using standard Developmental Psychology editorial guidelines, provides a solid and cuttingedge panorama of current developmental science approaches to understanding the individual and social contexts of youth violence development. The articles provide breadth and depth with respect to the study of risk and protective factors-including child characteristics, parenting behavior and family relationships, and exposure to deviant peers and media violence-and the ways in which these characteristics interface with community and neighborhood qualities to increase or decrease the likelihood of acute or chronic patterns of interpersonal violence. Careful attention is devoted to mechanisms of influence and to the proximal impact of cognitive and social-cognitive skills and processes in the acquisition and maintenance of antisocial behavioral styles.

Of special note is the effort made in several studies to describe carefully trajectories of growth and development in violence across the childhood and adolescent years. We now have the analytic tools, the accumulating longitudinal data, and the measurement sophistication to test specific theories of how violent tendencies emerge, become consolidated, and change in response to normative and nonnormative life experiences. Such theorydriven inquiry may be usefully guided by developmentally sensi- 
tive, transactional models of antisocial behavioral development, such as the biopsychosocial model detailed in this special issue.

Less well represented in this special issue are studies focusing on genetic and biological factors, studies designed to evaluate (or contrast) violence prevention programs, and studies focusing on the impact of specific social policies. Only one of the reports in this special issue used a genetic design, and only two were concerned with the explicit evaluation of school-based preventive interventions. None of the articles included here is concerned with direct empirical evaluation of social policies as they bear on childhood violence. Whether these relative proportions (i.e., higher numbers of articles with a basic developmental science focus, fewer articles devoted to program or policy evaluation) represent general trends in the literature or merely the vicissitudes of constructing a special issue in a developmental-science-oriented journal, we cannot be sure. In any event, we believe that the reports contained here are valuable and laudable. As noted in the expert commentary provided by Michael Rutter, they provide differing starting points in the study of the causal processes in the development of childhood violence, and they provide the beginnings of a bridge across science, programming, and policy. There are both convergence and divergence in methods and results, in the theo- retical underpinnings of the approaches used, and in interpretive templates that were applied. The resulting collection, we believe, can serve an important function in drawing attention to the important work being conducted on childhood violence and in providing a solid foundation for future developmental inquiry.

\section{References}

Bipartisan Working Group on Youth Violence, U. S. House of Representatives. (1999, November). Final report to the 106th Congress. Retrieved June 24, 2002 from http://www. house. gov/frost/youthviol. htm

Cicchetti, D., \& Toth, S. L. (2000). Editorial: Social policy implications of research in developmental psychopathology. Development and Psychopathology, 12, 552-554.

Moore, M. H., Petrie, C. V., Braga, A. A., \& McLaughlin, B. L. (Eds.) (2002). Deadly lessons: Understanding lethal school violence. Washington, DC: National Research Council.

Smith, D. C., \& Furlong, M. J. (1998). Introduction to the special issue: Addressing youth anger and aggression in school settings. Psychology in the Schools, 35, 201-203.

Weist, M. D., \& Cooley-Quille, M. (2001). Advancing efforts to address youth violence involvement. Journal of Clinical Child Psychology, 30, $147-151$. 